\title{
Understanding radon sources and mitigation in buildings
}

Received (in revised form): 28th April, 2005

\begin{abstract}
Daryl Dixon
has worked in radiation protection for over 20 years, formerly providing advice and services to industrial and academic users and since 1990 has managed the NRPB programme on radon. During most of this time, he has maintained a particular interest in natural sources of exposure, including occupational exposure to radon in buildings, mines and caves and more recently in the natural gas and water industry. He has conducted and published studies on many aspects of radon measurement and exposure management and has published numerous papers and reports. He also routinely presents seminars and training courses to professionals and other groups. He advises a number of industrial and commercial companies on procedures to reduce radiation exposures and works closely with stakeholders to develop practical and proportionate advice. Current activities include the development of initiatives to enhance awareness about radon amongst public and professional groups and development of radon risk assessment procedures for employers.
\end{abstract}

\section{Chris Scivyer MCIOB}

is a chartered builder who has been involved in BRE's programme of radon research and guidance since 1986 . He has had responsibility for developing practical and cost effective protective measures for new buildings. This work included site observational studies and measurements in over 500 houses, and assisting in developing guidance which supports UK Building Regulations. Chris has also been involved with BRE's work in existing buildings, which has included, home visits, field trials of remedial measures, managing a telephone hotline, and providing advice at radon surgeries. He has also assisted with research in schools and developing technical training material in Ireland, and field trials in Hong Kong. As a result of this work Chris has been sole or joint author of numerous papers and guides on radon remedial measures. Chris regularly attends national and regional radon steering groups and presents lectures on radon for construction professionals, local authorities, and members of the general public. He has represented the UK at international radon conferences throughout Europe, the USA, and Canada, and recently co-ordinated the European Radon Research and Industry Collaboration Concerted Action (ERRICCA 2), which was responsible for establishing National Radon For a 21 European countries.
Abstract
Radon is the largest source of radiation exposure for most people and has been shown clearly to be responsible for an increased risk of lung cancer. Over the last two decades, the UK has undergone a vigorous programme of work to identify homes with high radon levels and encourage occupiers to reduce their exposures. Much of the development and management of this programme was conducted by the Radiation Protection Division of the Health Protection Agency (HPA), formerly the National Radiological Protection Board (NRPB), and involved collaboration with many academic workers, professionals, government officers and employers.
Based on experience and feedback from these contacts and measurement campaigns, the NRPB continues to develop new initiatives and programmes to promote greater reduction of doses 
Levels can be very high in some buildings

\section{Radon causes the longest dose for most people}

potentially very influential group with an important role in raising awareness about radon and its reduction. This paper summarises the mechanisms and features of radon mitigation for professionals who might wish to advise occupiers or contractors about radon, focusing on the choice and effect of mitigation systems. The paper also reflects the current position on important elements of radon protection strategy, including identification of high-level areas, the suitability of measurement procedures and targets for dose reduction.

\section{Keywords:}

radon, radiation, health, risk, protection

\section{INTRODUCTION}

Many householders and employees in buildings across the country are unaware that they are being exposed to excessive levels of the radioactive gas radon (Wrixon et al., 1998). This gas is present naturally in the ground and causes an increased risk of lung cancer when breathed in. It is estimated that between 1,000 and 2,000 deaths per year are caused by exposure to radon.

An unusual feature of radon in buildings is the very large range over which levels can vary, typically from background levels of about $20 \mathrm{~Bq} \mathrm{~m}^{-3}$ to more than a thousand times higher (Organo et al., 2004). Fortunately, radon levels almost always can be reduced with simple building works, so occupiers of buildings in radon-prone areas can be encouraged to undertake measurements in the knowledge that if levels are high they will be able to benefit from a significant reduction in their individual risk.

The potential presence of radon in a building is also of interest to professionals who are involved in the sale and purchase of buildings. As part of the conveyancing process, many solicitors are required to respond formally to a question about whether a property might be affected by radon. As awareness of radon increases, building surveyors, valuers and other property advisers will need to respond to questions and concerns about radon. There is, therefore, considerable scope for professional groups to contribute to the programme to reduce people's exposure to radon.

The Radiological Protection Division (RPD) of the HPA provides a national point of reference on the risks and measurement of radiation and also works closely with others to raise awareness about radon and promote protection initiatives. The RPD also has close links with the Building Research Establishment (BRE), the organisation which leads research into effective ways of reducing radon levels. This paper provides background material on the origins and mitigation of radon in buildings and draws on a previous study of the design and effect of mitigation systems (Naismith et al., 1998), which should also be consulted.

\section{RISKS AND PROTECTION STRATEGY}

Radon and certain of its decay products break down with the emission of alpha particles which are very damaging to living cells. Because it is a gas, radon and its decay products can be inhaled, delivering radiation energy 


\section{An atlas shows areas prone to radon}

to sensitive cells in the lungs and causing changes that increase the risk of lung cancer later in life (NRPB, 2000). Radon generally causes by far the largest proportion of radiation exposure to members of the public. The effect of prolonged exposure to radon has been identified from many international studies that investigated the health of exposed groups (eg Darby et al., 2004). This quantification of the risk provides a firm basis for national standards.

In 1990, the UK Government adopted the current Action Level of $200 \mathrm{~Bq} \mathrm{~m}^{-3}$ - a value ten times higher than the national average concentration in homes (NRPB, 1990). The Action Level refers to the average long-term concentration. A recent re-analysis of 13 major health studies (Darby et al., 1998) demonstrated excess risk from radon exposure below the Action Level; the RPD is considering whether the radon policy should be updated.

The RPD has conducted measurements in nearly half a million houses since the early 1990s, mostly under government programmes to find houses with radon levels above the Action Level (Dron, 1994). Over 200,000 of these measurements were used to produce an atlas of radon potential which was published in 2002 (Green et al., 2002). One of the plates from the Atlas is show in Figure 1. It is estimated that there are

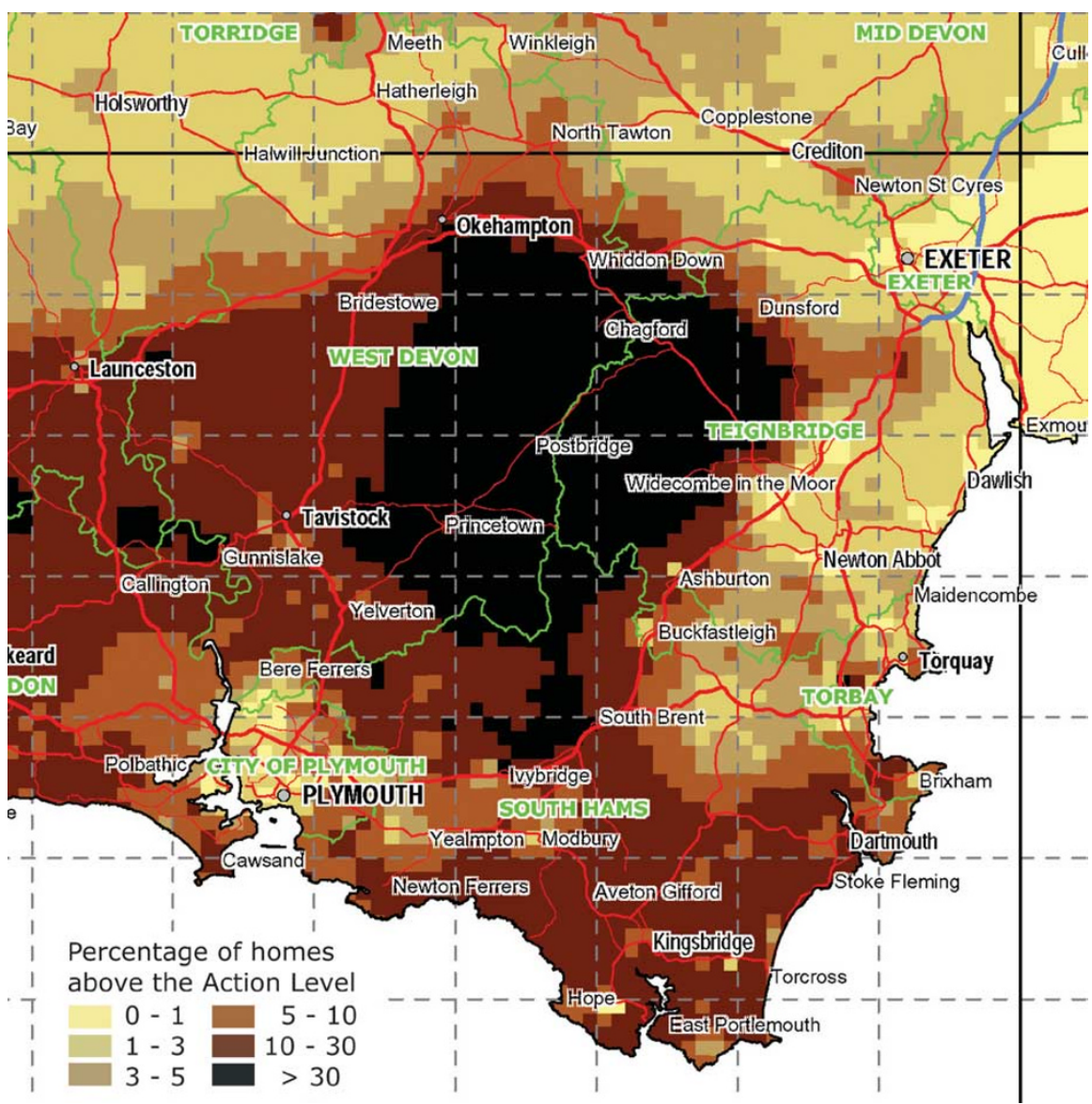

Figure 1: Radon affected areas 
Employers must assess risks from radon more than 100,000 houses in the UK with radon above the Action Level (Kendall et al., 1994). Resources are directed to areas with the greatest risk from radon by designating them as Affected Areas, defined as those where more than 1 per cent of houses are predicted to have radon levels above the Action Level. Affected Areas are currently identified in the Radon Atlas of England and Wales (Green et al., 2002) by reference to Ordnance Survey grid lines, but more detailed maps are likely to become available in due course (Miles and Appleton, 2000).

There are also many workplaces in radon-prone areas and employers in such places are required by law to evaluate the risks from hazards in their premises (HSE, 1999), which is generally interpreted as a requirement to measure radon in buildings in Affected Areas. The employer is required to introduce formal measures to prevent or restrict exposure if radon levels exceed $400 \mathrm{~Bq} \mathrm{~m}^{-3}$. The different Action Level for workplaces reflects shorter occupancy. Studies suggest (Ross et al., 1994) that significant numbers of employees work routinely in radon levels above $1,000 \mathrm{~Bq} \mathrm{~m}^{-3}$ and, therefore, unless levels are reduced, may require formal designation as radiation workers.

There is frequent demand from householders and employers wishing to know whether their premises are in an Affected Area and there are a number of commercial search services that use the RPD radon data. The RPD has also recognised the need for providing guidance to corporate owners of large building stocks and it advises them on a protection strategy and priorities for measurement and mitigation.

Enquiries about radon are often directed to local surveyors and others with a technical background who may wish to advise on mitigation work. The RPD maintains contact with many professionals in a range of disciplines and aims to support and encourage their responses to radon enquiries (Dixon, 2001). There is a particular need to strengthen the advice and services provided to occupiers who wish to mitigate radon. Most mitigation projects are well within the capability of many local builders, but demand is quite low so most builders have little experience and relatively little professional support, beyond some standard literature (BRE, 1993-2001). There is scope for developing support and skills for a range of professionals with appropriate levels of training and performance monitoring.

\section{SOURCES AND MOVEMENT OF RADON INTO BUILDINGS}

The radon level in a building is determined by the following principal factors, which are illustrated schematically in Figure 2 and discussed in detail below.

- Concentration of radioactivity in the ground

- Permeability of the ground

- Nature of floor and coupling of building to the ground

- Ventilation conditions in the building.

The highest radon levels occur where each of these factors works to increase the radon, but small changes in one or more of them can cause 


\section{A measurement is essential to find high levels}

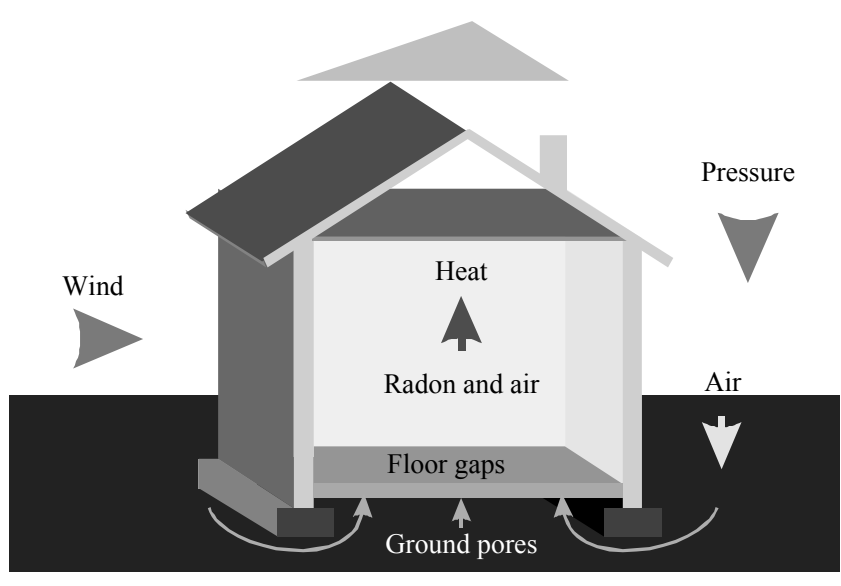

Figure 2: Radon entry into buildings

appreciable differences in the radon level, even in adjacent buildings of apparently identical construction (Cliff et al., 1984). Consequently, it is not normally possible to make any quantitative judgment about these factors from a visual inspection or any rapid assessment procedure. A measurement, therefore, always will be required to determine the level of risk to occupants. A thorough grasp of the physical principles involved, however, can provide some insight when making decisions about the likely suitability and effect of remedial options.

\section{Concentration of radon in and movement through the ground}

All ground contains traces of uranium, the natural radioactive element that produces radon, with the result that radon levels in soil gas are invariably high, rarely less than several thousand $\mathrm{Bq}^{-3}$. Depending on the nature and configuration of a building, therefore, the possibility of high radon levels cannot be excluded anywhere in the UK, particulary in locations below ground level. While there are a number of geographical areas with high levels of radioactivity in the ground, high radon levels are not, as is often thought, confined to these areas but occur in many other areas.

The permeability of the ground also affects radon levels in overlying buildings. Soil gas containing radon can be drawn from deep underground and, even when the concentrations in soil gas are relatively low, can increase the radon level in occupied spaces. In particular, high radon levels commonly occur in properties over rock types such as limestone and chalk, largely because of their permeability. Clay, when wet, can provide an effective barrier against gas movement, but if it dries out and cracks the barrier effect is lost. In extreme cases, where properties are close to metal ore mines or strata, very high radon levels can seep into buildings and this is thought to be the cause of the extremely high levels mentioned earlier. Furthermore, there can be large variations in radon potential over short distances caused by local mineralisation, changes in rock type or properties and the nature of the overlying layer of drift. 


\section{There are large natural variations in levels}

In short, the type of ground underlying a building provides only an indicative guide to the radon level.

\section{Movement of radon into and within a building}

The amount of radon that is drawn into a building depends on the driving force, which is pressure difference, and the degree of coupling between the ground and the building. The air pressure in a heated building normally will be lower than outdoors so radon-laden air is pulled into the building from the ground. The pressure difference inside a building reflects the difference in temperature inside and outside the building so the driving force for radon input changes with the heating level and outdoor temperature. This causes highest radon levels at night; a similar effect causes radon levels to vary with the seasons, with the highest levels occurring in winter. Test results that are to be compared with the Action Level, therefore, must be adjusted to compensate for seasonal variations. Natural variations in the weather also affect radon movement and higher levels are to be expected indoors when the atmospheric pressure is falling, but this has a relatively small effect on the measurement.

In general, good ventilation under a suspended floor will work to reduce radon levels in a building, while a solid floor, particularly if it is cracked or leaky, can provide an easy and direct path for radon ingress. In addition, cracks around the edges of concrete floors and service entries such as water and sewage pipes or electricity cables also may increase radon ingress. The presence of basements, voids or ducts under a building can complicate matters, as can foundation walls extending down into the ground. Radon levels in rooms below ground level are difficult to predict as there may be different ventilation characteristics and ingress of radon from all surfaces that are in contact with the ground.

In practice, the design, structure and quality of buildings is extremely variable. Many properties will be joined to others, have extensions or modifications or simply may have a mixture of design features. Such factors can have an important effect on radon movement and the choice of mitigation system.

Once inside a room, radon build-up is affected by ventilation, which is determined by factors such as draught-proofing, occupancy patterns and the amount of heating. Radon levels in a property, therefore, are likely to vary with the occupants and possibly with changes to their circumstances. Increased ventilation will not always decrease the radon concentration, however, because extract fans or open windows on an upper floor can lower indoor pressure and increase radon ingress. The effect of these factors varies greatly between buildings and can lead to large and sometimes surprising differences in radon levels.

The range of factors affecting ventilation mean that management of radon levels through ventilation is not an effective means of control, particularly since radon levels are typically higher at the coldest times of the year. Given the influence of lifestyle factors on radon levels, it is not unusual for repeat measurements of radon in a building to differ, particularly following changes to draught-proofing, windows or building an extension. 
Table I: Method of operation of principal radon mitigation methods

\begin{tabular}{|c|c|c|}
\hline Remedial type & Method of operation & Effectiveness* \\
\hline \multicolumn{3}{|l|}{ Below floor } \\
\hline Sump & $\begin{array}{l}\text { Soil gas drawn into low-pressure } \\
\text { cavity and exhausted outside }\end{array}$ & $\begin{array}{l}\text { Usually very good, commonly a } \\
\text { factor of ten or more reduction }\end{array}$ \\
\hline Ventilation & $\begin{array}{l}\text { Increased volume of fresh air } \\
\text { dilutes radon concentration }\end{array}$ & $\begin{array}{l}\text { Can be very effective with } \\
\text { unobstructed air path }\end{array}$ \\
\hline \multicolumn{3}{|l|}{ Above floor } \\
\hline Powered ventilation & $\begin{array}{l}\text { Increased pressure and } \\
\text { ventilation in living areas }\end{array}$ & Fairly effective in well-sealed buildings \\
\hline Natural ventilation & $\begin{array}{l}\text { Increased volume of fresh air } \\
\text { dilutes radon concentration }\end{array}$ & Not usually very effective \\
\hline Sealing & $\begin{array}{l}\text { Increased resistance to flow } \\
\text { of soil gas into living areas }\end{array}$ & Usually ineffective \\
\hline
\end{tabular}

*For a simple structure without adjoining structures, basements or major modifications.

Table 2: Radon reports from the BRE

\begin{tabular}{lll}
\hline Report number & Title & Publication date \\
\hline Series of guides on radon remedial measures in existing dwellings & \\
BR 227 & Radon sump systems, 2nd edition & 1998 \\
BR 239 & Sealing cracks in solid floors & 1993 \\
BR 250 & Surveying dwellings with high indoor radon levels & 1993 \\
BR 267 & Major alterations and conversions & 1994 \\
BR 270 & Protecting dwellings with suspended timber floors & 1994 \\
BR 28I & Positive pressurisation & 1995 \\
BR 343 & Dwellings with cellars and basements & 1998 \\
Other reports & & 1995 \\
BR 293 & Radon in the workplace & \\
\hline
\end{tabular}

\section{MITIGATION SYSTEMS}

The method of choice for mitigation depends on the required reduction factor and the type of floor (Scivyer et al., 1993). In general, the best way in which to lower radon levels is to reduce the pressure difference that

\section{Reduction method} depends on floor type

\section{A radon sump is the best method} draws radon into a building. Dilution or an effective barrier are generally less effective and normally should not be the method of first choice, although they might be useful in combination with other methods. Table 1 shows the effect and actions of the principal methods that have been developed as radon remedies, which are described in detail below. More detail is provided in technical reports issued by the BRE and listed in Table 2 .

\section{Sump (solid floor only)}

A radon sump is a hole or void of volume around $10-25 \mathrm{~L}$ created beneath the floor slab and linked by pipework to the outside. The sump void sometimes can be produced by boring through an external wall below floor level. An electric fan in the pipework draws air from the sump, reversing the pressure difference that draws radon into the room, and discharges the radon-laden air outside. Sumps work most effectively where the fill beneath the slab is particularly permeable and are generally effective for an area about the size of a typical house, except where the substrate is particularly unfavourable. Mitigation of properties with 
concrete floors poured directly onto rock or a property or houses on different levels, for example, may require additional sumps. Depending on accessibility beneath the floor, sumps also can be used where there is a concrete layer over the soil under a suspended wooden floor.

\section{Assisted underfloor ventilation (suspended floor only)}

Radon levels under a suspended floor often can be diluted with a fan mounted in the wall to blow air into or draw it from the underfloor space. The effect on the radon level, however, depends in a complicated way on how air moves into and around the space and the design or operation of a system sometimes can require subtle adjustments. The choice of fan mode depends on the local characteristics of the ground and the property construction and may require experimentation. It is essential, however, to avoid drawing damp air under the floor or otherwise creating conditions that will cause timber to rot.

\section{Natural underfloor ventilation (suspended floor only)}

Some improvement of underfloor airflow sometimes can be achieved with additional airbricks or by replacing existing ones. Plastic airbricks with a large open area can increase ventilation under the floor significantly, providing there are no obstructions such as foundations or stub walls. Ideally, airbricks should be on at least two opposite walls and should provide at least $1,500 \mathrm{~mm}^{2}$ of open area for each metre run of wall.

\section{Assisted room ventilation}

Room ventilation fans are generally operated intermittently so do not

Natural ventilation or sealing are not usually very effective affect the long-term radon level significantly. Permanent extra room ventilation can be introduced into a building using commercial systems that blow filtered air from the roof space into the house. These units are designed principally for reducing condensation, but they also increase the air pressure in the house slightly, particularly if it is well sealed, thereby reducing the ingress rate of radon-laden air from the ground. Individual room fans generally will not provide the extent or consistency of effect required for radon reduction.

\section{Natural room ventilation}

It is very difficult to achieve the permanent increase in natural room ventilation required for radon reduction by natural or passive means. A marginal increase in ventilation is possible with trickle vents fitted to windows, so that there is an open area, typically of $4,000 \mathrm{~mm}^{2}$ to $6,000 \mathrm{~mm}^{2}$ in each room, but this rarely will be adequate mitigation on its own. As noted earlier, ventilation solely on upper floors should be avoided as it can lower the indoor pressure causing greater ingress of radon from the ground. The presence of chimneys and regular use of open fires can compromise the remedial effect of room ventilation.

\section{Sealing}

Sealing aims to prevent the bulk movement of air containing radon into occupied areas. Since the pressure difference between the ground and 
Monitors are simple and unimpressive the building is unaffected, however, radon will continue to be drawn in unless essentially all ingress points are effectively sealed. Many cracks and gaps will be obscured by skirting boards, carpets and other decorative features so effective sealing is extremely difficult to achieve in practice and sealing all cracks and entry points is generally not a practicable option.

\section{TESTING FOR RADON}

The most important advice to householders in Affected Areas is that they should arrange a measurement and reduce the radon level if it is found to be high. Uncertainty about radon may be an obstacle to the purchase of a property and there is a clear benefit in arranging a measurement well in advance of any proposed sale. In the large majority of cases, even in Affected Areas, the result will be below the Action Level and may reassure occupants.

The variability of radon levels in buildings means that the risk cannot be estimated reliably from a brief test or inspection. Low pressure or stormy conditions, for example, can lead to a sudden and potentially large increase in levels, so it is not practicable to estimate an accurate long-term average radon level from short duration measurements. Figure 3 shows the variation in radon levels in a school and indicates the considerable scope for measuring a radon level that differs from the long-term average. A measurement, even over several days, would be quite likely to provide a result that differs from the true long-term value, leading either to under-protection or expenditure on unnecessary mitigation work.

The key to a reliable estimate of radon exposure is to measure over a sufficiently long period to average out the short-term variations. Great caution is required if advice about the need for action is to be decided upon based on a measurement shorter than about 14 days. The RPD generally recommends radon measurements over a nominal period of three months (Miles and Howarth, 2000). Passive monitors are very suitable for this purpose as they have no moving parts, are robust, cheap to use and can be sent through the post. The preferred measurement

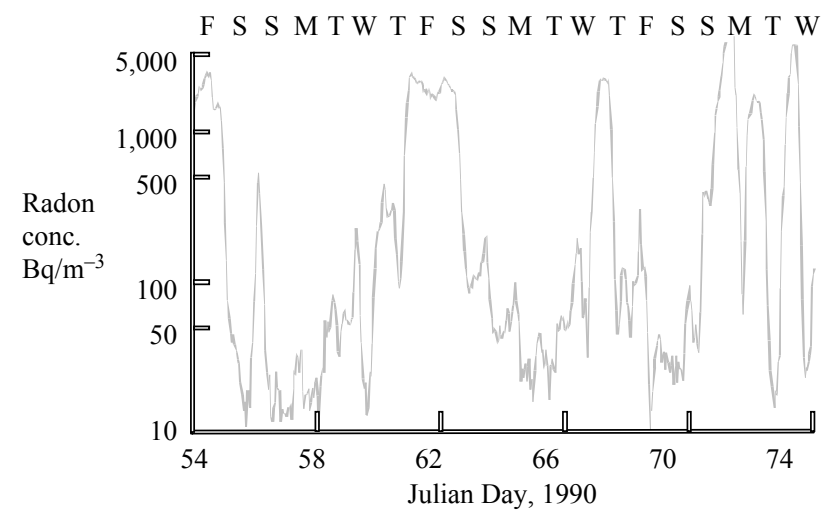

Figure 3: Variation of radon levels in a school 
Extra measurements are not usually needed to plan mitigation procedure in houses uses two radon monitors, one each for the main living area and bedroom, so that exposures can be estimated for typical patterns of occupancy (Wrixon et al., 1998).

Although the preference is for testing over three months, the RPD recognises that a test over a shorter period is sometimes required and is developing a screening procedure to give a general indication of radon levels from a measurement over two weeks. Screening tests, however, have much greater uncertainty and, for radon levels within a factor of two of the Action Level, will not provide a result on which further action can be based reliably. In such cases, a longer measurement will be required.

For conventional and typical size properties, it usually will be feasible to develop and specify a mitigation plan from the results of the initial three-month measurement. Occasionally, a contractor may wish to identify the location and strength of the radon source using short-term testing. The extra time and effort of such testing is only likely to be justified, however, in difficult or potentially costly cases, and where the test results will materially affect the design of the system. The measurement methods and procedures must be sufficiently similar that the results can be compared legitimately; local or short-term measurements cannot be used to improve or qualify the conclusions of previous tests.

\section{CHOOSING AND TESTING THE MITIGATION SYSTEM}

The RPD advises householders to seek the maximum reduction of the radon level and this requires the most effective remedy. Selection of a method that reduces the radon concentration to only just below the Action Level is to be avoided. The Action Level does not mark a boundary between safe and dangerous levels. Even radon concentrations below the Action Level carry a risk. Moreover, experience shows that many mitigation systems, even when apparently well specified, fail to deliver the expected reduction. Contractors sometimes choose a less effective mitigation option in the hope that it will be cheaper or less disruptive, but this may cost more in the longer run and discourage fully effective mitigation.

There is, in any event, some difficulty in designing a system for only a partial reduction in radon because of the potentially large impact of uncontrolled local factors on radon levels. Depending on the method, quality and duration of measurement, the result may vary by up to $100 \mathrm{~Bq} \mathrm{~m}^{-3}$ or more, so the mitigation system will require surplus capacity to allow for this uncertainty. If the risks of insufficient reduction and consequent additional redesign costs are to be avoided, therefore, a mitigation system should be selected to produce the maximum reduction in radon levels.

Table 3 shows preferred mitigation choices for maximum reduction of radon levels in different circumstances. Mixed floors present particular difficulties as radon may enter occupied rooms through the solid floor and also from beneath a suspended floor so it may be necessary to install multiple types of remedy. Selection of remedies in complex cases requires detailed understanding of radon sources and movement. There will be 
Table 3: Remedial method for maximum radon reduction

\begin{tabular}{|c|c|c|}
\hline $\begin{array}{l}\text { Reported radon } \\
\left(\mathrm{Bq} / \mathrm{m}^{-3}\right)\end{array}$ & Floor type & Radon reduction method \\
\hline \multirow{2}{*}{$200-300$} & Solid & Sump or positive ventilation \\
\hline & $\begin{array}{l}\text { Suspended } \\
\text { Mixed }\end{array}$ & $\begin{array}{l}\text { Assisted underfloor ventilation or positive ventilation } \\
\text { Positive ventilation }\end{array}$ \\
\hline \multirow[t]{3}{*}{$300-600$} & Solid & Sump or positive ventilation unless draughty \\
\hline & Suspended & $\begin{array}{l}\text { Assisted underfloor ventilation or positive ventilation unless } \\
\text { draughty }\end{array}$ \\
\hline & Mixed & Sump, may also need underfloor ventilation \\
\hline \multirow[t]{3}{*}{$600-1,000$} & Solid & Sump \\
\hline & Suspended & Assisted underfloor ventilation \\
\hline & Mixed & Sump and underfloor ventilation \\
\hline \multirow[t]{3}{*}{$1,000-2,000$} & Solid & Sump \\
\hline & Suspended & Assisted underfloor ventilation and sealing obvious gaps \\
\hline & Mixed & Sump and underfloor ventilation, also sealing obvious gaps \\
\hline \multirow[t]{3}{*}{ Above 2,000} & Solid & Sump, but assess ground conditions \\
\hline & Suspended & $\begin{array}{l}\text { Assisted underfloor ventilation and sealing obvious gaps, possibly } \\
\text { positive ventilation }\end{array}$ \\
\hline & Mixed & $\begin{array}{l}\text { Sump and underfloor ventilation, may also need positive } \\
\text { ventilation }\end{array}$ \\
\hline
\end{tabular}

Levels should be tested after mitigation occasions when advice will be required from specialists with experience of radon supported by the technical reports from the BRE listed in Table 2.

A measurement must always be taken immediately after the mitigation work to show that it has been effective. Once installed, the performance of a mitigation system will depend on the continued operation of various components, including the fan, and periodic testing is necessary to show that radon levels remain low, particularly if there have been alterations to a property in the intervening period. Periodic retest of protection systems is a formal requirement in workplaces.

\section{CONCLUSIONS}

Protection standards and strategies to limit exposure to radon in the UK are well developed and provide a framework within which professionals can make an important contribution. Essential elements are measurement of the radon level and the choice and delivery of a mitigation system to reduce high levels. The objective must be to build experience and confidence in radon work among builders. There is substantial scope for those involved in building appraisals, either as surveyors, valuers or property managers, to promote radon measurement and mitigation.

The principles of radon movement and accumulation in buildings will be familiar to those with a technical background. A thorough understanding will enable many professionals to assist builders and others to choose and design a suitable mitigation system. There is relatively little demand at present for training or support from mitigation contractors and wider involvement of other professionals could be a useful way in which to stimulate more awareness and mitigation.

The likelihood that mitigation work will be successful first time, the amount of disruption and the cost are important topics on which professionals can advise. If a remedy does not achieve the required 


\section{There is potential for large reductions in radiation dose}

reduction, further work will be required with additional inconvenience and delay. Furthermore, a multiple stage remedial programme may be more costly than a single, more effective approach. Mitigation work, therefore, should be designed to achieve maximum reduction of radon rather than relying on cheaper but less effective options.

The application and use of mitigation systems are reasonably well understood, but there are a number of issues such as the extent of radonprone areas, interpretation of measurements and the target for mitigation that still cause confusion. The presence of a body of professionals who understand and can explain these issues to contractors would be of considerable benefit. In addition, feedback from such professionals on the progress and effectiveness of radon mitigation work would assist the HPA to improve protection standards and promote dose reduction initiatives.

(C) Health Protection Agency 2005

\section{References}

BRE (1993-2001) Guides to Radon Remedial Measures in Existing Buildings. A series of easy to follow guides, Construction Research Publications Ltd, London, UK.

Cliff, K.D., Miles, J.C.H. and Brown, K. (1984) The Incidence and Origin of Radon and its Decay Products in Buildings. NRPB-R159, Chilton, UK.

Darby, S.C., Whitley, E., Silcocks, P., Thakrar, B., Green, M., Lomas, P., Miles, J., Reeves, G., Fearn, T. and Doll, R., (1998) 'Risk of cancer associated with residential radon exposure in South-West England: A case-control study', British Journal of Cancer, 78, 394-408.

Darby, S.C., Hill, D., Auvinen, A., Barros-Dios, J.M., Baysson, H., Bochicchio, F., Deo, H., Falk, R., Forastiere, F., Hakama, M., Heid, I., Kreienbrock, L., Kreuzer, M., Lagarde, F., Mäkeläinen, I., Muirhead, C., Oberaigner, W., Pershagen, G., Ruano-Ravina, A., Ruosteenoja, E., Schaffrath Rosario, A., Tirmarche, M., Tomáek, L., Whitley, E., Wichmann, H-E. and Doll, R. (2004) 'Radon in homes and risk of lung cancer; collaborative analysis of individual data from 13 European case-control studies', British Medical Journal, 330, 223-227.

Dixon, D.W. (2001) 'An overview of issues in the reduction of UK radon exposure', Environmental Management and Health, 12(5), 516-524.

Dron, E.M. (1994) 'UK radon programme: Policy and progress', paper presented at the First International Workshop on Indoor Radon Remedial Action, Rimini, Italy, June-July 1993, subsequently published in Radiation Protection Dosimetry, 56(1-4), 339-342.

Green, B.M.R., Miles, J.C.H., Bradley, E.J.B. and Rees, D.M. (2002) Radon Atlas of England and Wales. NRPB-W26, Chilton, UK.

Health and Safety Executive (HSE) (1999) The Ionising Radiations Regulations 1999. Statutory Instrument 1999 No. 3232, HMSO, London, UK.

Kendall, G.M., Miles, J.C.H., Cliff, K.D., Green, B.M.R., Muirhead, C.R., Dixon, D.W., Lomas, P.R. and Goodridge, S.M. (1994) Exposure to Radon in UK Dwellings. NRPB-R272, Chilton, UK.

Miles, J.C.H. and Appleton, J.D. (2000) Identification of Localised Areas of England Where Radon Concentrations are Most Likely to have Greater Than 5\% Probability of Being Above the Action Level. DETR Report No. DETR/RAS/00.01, London, UK.

Miles, J.C.H. and Howarth, C.B. (2000) Validation Scheme for Laboratories Making Measurements of Radon in Dwellings: 2000 Revision. NRPB-M1140, Chilton, UK.

Naismith, S.P., Miles, J.C.H. and Scivyer, C.R. (1998) 'The influence of house characteristics on the effectiveness of radon remedial measures', Health Physics, 75(4), 410-6.

NRPB (1990) Limitation of Human Exposure to Radon in Homes. Statement by the NRPB, Doc. NRPB, Vol. 7(2), 1-9. National Radiological Protection Board, Chilton, UK.

NRPB, Faculty of Public Health Medicine and Chartered Institute of Environmental Health (2000) Health Risks From Radon. National Radiological Protection Board, Chilton, UK.

Organo, C., Ellard, A., Fenton, D., Synnott, H., O’Colmain, M., Prenter, S., O’Reilly, S. and Colgan, P.A. (2004) 'High radon concentrations in a house near Castleisland, 
County Kerry (Ireland) - Identification, remediation and post-remediation', Journal of Radiological Protection, 24, 107-20.

Ross, B.C., Atkinson, M.R. and Dixon, D.W. (1994) 'Regional variations in occupational exposure to radon and the resulting regulatory action', paper presented at the First International Workshop on Indoor Radon Remedial Action, Rimini, Italy, June-July 1993, subsequently published in Radiation Protection Dosimetry, 56(1-4), 287-290.

Scivyer, C.R., Wooliscroft, M. and Parkins, L. (1993) 'The development and implementation of radon remedial measures in UK dwellings', paper presented at the International Conference on Radon and Radon Remedial Measures, Denver, CO, September.

Wrixon, A.D., Green, B.M.R., Lomas, P.R., Miles, J.C.H., Cliff, K.D., Francis, E.A., Driscoll, C.M.H., James, A.C. and O'Riordan, M.C. (1998) Natural Radiation Exposure in UK Dwellings. NRPBR190, HMSO, London, UK. 